\title{
EXTRACTIVE ACTIVITIES: EVIDÊNCIAS EMPIRÍCAS AO DISCUSSION PAPER DO IASB
}

\author{
Odilanei Morais dos Santos' \\ Paula Danyelle Almeida da Silva ${ }^{2}$
}

Resumo: O presente trabalho teve como objetivo fornecer evidências empíricas à questões chaves do Discussion Paper Extractive Activities colocadas em discussão pelo International Accounting Standard Board e que tratam da norma contábil internacional aplicável às empresas extrativistas. Trata-se de contribuição efetiva da academia ao processo de regulação contábil internacional. Para operacionalizar os estudos, utilizou-se a base de dados da Evaluate Energy ${ }^{\oplus}$, empregando-se regressões com dados em painel a diversos planos amostrais contendo informações de empresas petrolíferas. Os resultados indicaram que o atual conjunto de informações baseado no custo histórico é relevante para as decisões econômicas dos participantes do mercado de capitais. Assim, tem-se um cenário para se acreditar na manutenção do status quo vigente.

Palavras-chave: IFRS 6; Extractive Activities; Value Relevance; Empresas Petrolíferas.

${ }^{1}$ E-mail: odilaneisantos@terra.com.br - Universidade Federal do Rio de Janeiro

${ }^{2}$ E-mail: pauladanyelle@terra.com.br - PETROBRAS

- DOI: http://dx.doi.org/10.14392/asaa.2015080301

- Artigo recebido em 20/10/2014. Revisões requeridas em: 02/11/2015 e aprovado em 04/12/2015. 


\title{
EXTRACTIVE ACTIVITIES: EMPIRICAL EVIDENCE ON DISCUSSION PAPER OF IASB
}

\begin{abstract}
This paper aimed to provide empirical evidence for the key issues of Discussion Paper Extractive Activities placed on the public audience by International Accounting Standard Board relative the international accounting standard applicable to the extractive companies. It is effective contribution of academia to the international accounting regulation process. To operationalize the studies, the database of Evaluate Energy ${ }^{\circledR}$ was deployed, through the use of regressions panel data, in various sampling plans featuring information of the oil companies. The results indicated that information based on the historical cost is relevant to economic decisions by the participants of the capital market. Therefore, there is scenario to believe in the maintenance of the present status quo.
\end{abstract}

Keywords: IFRS 6; Extractive Activities; Value Relevance; Oil Companies. 


\section{INTRODUÇÃO}

$\mathrm{N}$ os últimos anos, presenciou-se um grande movimento mundial em direção à convergência para as práticas contábeis internacionais emanadas pelo International Accounting Standard Board IASB, não sendo diferente no Brasil, cujo maior passo foi dado no final de 2007 com a aprovação da Lei no. 11.638, que alterou práticas contábeis relevantes na Lei nº. 6.404/76 e exigiu o alinhamento com os padrões contábeis internacionais.

Subjacente a esse marco da contabilidade no Brasil e no mundo, tem-se a discussão a respeito do processo de regulação contábil, para cujo entendimento, segundo Cardoso et al (2009), pouca ênfase tem sido dispensada. Martins (2014), inclusive, fez severas críticas à participação da academia no processo de regulação contábil, existindo uma inversão de papéis, com os emissores de normas atuando fortemente no campo teórico (papel reservado a academia!), enquanto que as pesquisas empíricas sobre a utilidade das normas contábeis, seus problemas teóricos, custos e outros aspectos não tem chegado ao conhecimento dos órgãos normativos.

Nesse contexto, o objetivo deste estudo é apresentar evidências empíricas à questões colocadas em discussão pelo IASB decorrente do processo de revisão/substituição da norma IFRS 6 (International Financial Reporting Standard n 6 - Exploration for and Evaluation of Mineral Asset), fornecendo um panorama que possa contribuir com a decisão sobre a necessidade, ou não, de mudanças no arcabouço contábil normativo aplicado as empresas do setor extrativista. Notadamente, utiliza-se o Discussion Paper Extractive Activities (DPEA daqui em diante), o qual foi colocado em audiência pública no ano de 2010.

O DPEA trouxe para discussão dez questões sobre temas relacionados a critérios para reconhecimento e mensuração das transações e sobre a necessidade de divulgação em nota explicativa de informações complementares. Dentre as questões do DPEA, a $6^{\mathrm{a}}$ e $9^{\mathrm{a}}$ apresentam demandas que podem ser respondidas empiricamente e que são o objeto deste estudo.

Busca-se, então, responder a seguinte questão de pesquisa: o que dizem as evidências empíricas relacionadas às propostas de reconhecimento a custo histórico ( $6^{\mathrm{a}}$ questão) e de divulgações obrigatórias (9a questão) no contexto da norma contábil internacional aplicável ao setor extrativista?

Assim, as evidências empíricas às demandas das questões 6 e 9 apresentadas no DPEA são contribuições efetivas que podem ser utilizadas pelos diversos interessados no processo de construção da norma internacional aplicada ao setor extrativista na fundamentação de seus argumentos, sejam a favor ou contra as propostas do IASB.

Para se alcançar o objetivo proposto, são modeladas regressões com dados em painel em amostras contendo informações que variam de 369 a 559 observações de empresas do setor petrolífero dos anos de 2005 a 2011.

Os resultados indicam que o atual conjunto de informações baseado no custo histórico e grande parte das divulgações já realizadas são relevantes para as decisões econômicas dos participantes do mercado de capitais, tendo-se, assim, um cenário para se acreditar na manutenção do status quo vigente. 


\section{REFERENCIAL TEÓRICO}

O debate colocado em discussão pelo IASB referente às normas contábeis aplicáveis às atividades petrolíferas orbita em dois grandes temas: (1) mensuração a custo histórico versus mensuração a valor justo e (2) divulgação de informações obrigatórias nas demonstrações financeiras.

\subsection{CUSTO HISTÓRICO VERSUS VALOR JUSTO}

No debate entre a metodologia de mensuração que apresenta maior utilidade aos usuários da informação contábil, existe a concepção, no setor petrolífero, de que os números contábeis produzidos com base no custo histórico, tendo por base os métodos contábeis dos esforços bem sucedidos e da capitalização total, são irrelevantes para os usuários da informação, e que as informações geradas em bases alternativas de mensuração (por exemplo: custo corrente, valor de mercado corrente, valor realizável líquido ou valor presente de fluxos de caixa futuros) forneceriam informações mais úteis (Raman \& Tripathy, 1993).

Raman e Tripathy (1993) argumentam que essa concepção decorre do fato de que a correlação entre os custos incorridos na exploração de óleo e gás e o valor monetário das descobertas das reservas minerais é geralmente baixa. Essa baixa correlação reside no fato de que o custo histórico reflete apenas os gastos para explorar e desenvolver as reservas de hidrocarbonetos e não o valor justo dessas reservas (Spear, 1996). Dessa forma, o valor histórico tem sido percebido como não adequado para a avaliação do valor das empresas petrolíferas (Harris \& Ohlson, 1987).

No setor petrolífero, esse debate não é novo e remonta a década de 1970, quando foi estabelecido o marco regulatório contábil do setor petrolífero no mercado norte-americano, e tem sido um tema recorrente sempre que se discutem os modelos contábeis do setor.

De acordo com Santos e Silva (2014), mundialmente as empresas petrolíferas seguem um dos seguintes métodos contábeis: esforços bem sucedidos e capitalização total. A diferença principal entre esses métodos reside na definição de quais gastos incorridos na fase exploratória de um projeto de exploração e produção de petróleo podem ou não ser tratados como ativo, sendo o primeiro método mais restritivo quanto a essa questão, ao passo que no segundo todos os gastos incorridos podem ser ativados.

No passado, já se tentou introduzir um modelo de reconhecimento dos ativos de óleo e gás com base em seu valor econômico com a emissão do Accounting Series Release n 253 (ASR 253). A Securities and Exchange Commission (SEC) declarou, nesse release, que tanto o método dos esforços bem sucedidos quanto o da capitalização total possuíam limitações para refletir substancialmente os eventos econômicos das atividades petrolíferas e instituiu o método de mensuração e reconhecimento conhecido como Reserve Recognition Accounting (RRA) (Adkerson, 1979).

O RRA consistia em um método para valorar monetariamente as reservas de óleo e gás descobertas e reconhecê-las no balanço como um ativo da empresa, não levando em consideração a metodologia tradicional do custo histórico como base de valor (Brock, Carnes \& Justice, 2007).

A relevância das informações geradas pelo RRA foi objeto de algumas pesquisas realizadas à época, mas os resultados não foram conclusivos. Em algumas delas, apontou-se a superioridade do custo como base de valor (Harris \& Ohlson, 1987; Herris \& Ohlson, 1990), enquanto que outras indicaram que as 
informações produzidas pelo RRA eram mais úteis (Kennedy \& Hyon, 1992; Chung, Ghicas \& Pastena, 1993; Boone, 1998; Boone, 2002), ou tais resultados foram inconclusivos (Doran, Collins \& Dhaliwal, 1988).

A SEC, contudo, foi alvo de pressões por parte de contadores e auditores, pautadas em fortes argumentos técnicos contra o método proposto (RRA), principalmente no que diz respeito à dificuldade encontrada na mensuração segura das reservas de óleo e gás e no custo de se produzir as informações e o ASR 253 foi abandonado (Adkerson, 1979; Connor, 1979; Cooper et al, 1979).

Com o abandono do RRA pela SEC, as reservas de óleo e gás deixaram de ser reconhecidas como ativo pelas empresas petrolíferas, mas em compensação, em 1982, o FASB emitiu o Statements of Financial Accounting Standard n ${ }^{\circ} 69$ - Disclosures About Oil and Gas Producting Activities (SFAS 69), obrigando as empresas a divulgarem, em notas explicativas, por ocasião das demonstrações financeiras anuais, um conjunto de informações adicionais visando fornecer esclarecimentos sobre suas atividades de prospecção e produção de óleo e gás. Tais informações complementares são conhecidas como SMOG (Standardized Measure of Oil \& Gas). Na próxima seção, detalham-se as questões relacionadas às divulgações obrigatórias.

Barth (2006) argumenta que, apesar de não ser um tema novo, o uso de estimativas futuras (fair value) nas demonstrações financeiras tem aumentado, em função da crença dos emissores de normas de que essa base de mensuração possibilita maior utilidade das informações contábeis para as decisões econômicas dos usuários (objetivo das demonstrações financeiras), por melhor refletir as condições econômicas das empresas.

Berry e Wright (2001), por outro lado, defendem a ideia de que, independentemente das características da empresa e do método contábil utilizado, as informações baseadas no custo histórico são relevantes aos usuários e que os "normatizadores não devem abandonar o custo histórico em favor, exclusivamente, da divulgação de informações relacionadas às reservas." (Berry \& Wright, 2001, p. 767).

Consequentemente, a dualidade entre o custo histórico versus valor justo também se fez presente no DPEA. O grupo de trabalho responsável, fazendo referência as bases para conclusões do SFAS 19 e SFAS 69, as quais apontam que o grau de incerteza e a subjetividade inerente à determinação das premissas visando se estimar o valor justo, ou valor corrente dos ativos de óleo e gás, não resulta em informações que podem ser suficientemente realistas e comparáveis para ser usadas como base de mensuração das demonstrações financeiras; argumenta que as conclusões do FASB levaram em consideração o ambiente econômico/tecnológico de mais de vinte e cinco anos atrás e que atualmente, os argumentos utilizados não permanecem necessariamente válidos, motivo pelo qual se traz a discussão novamente à tona (IASB, 2010a).

Como os usuários das demonstrações financeiras estão interessados em avaliar a capacidade de a empresa gerar fluxos de caixas futuros, a mensuração a valor justo é vista como conceitualmente consistente com os objetivos das demonstrações financeiras (IASB, 2010a).

O DPEA traz três abordagens para estimativa do valor justo dos ativos de óleo e gás: abordagem do mercado; abordagem do custo; e abordagem do lucro. No primeiro caso, o valor justo seria determinado por meio do uso de preços e outras informações relevantes geradas pelo mercado em transações envolvendo ativos idênticos ou comparáveis. No segundo caso, o valor justo seria baseado no montante exigido para repor a capacidade de serviço do ativo (custo de reposição). Por fim, na terceira abordagem, o valor justo seria determinado com base na estimativa do fluxo de caixa futuro descontado.

Considerou-se que as duas primeiras abordagens não eram aplicáveis aos ativos de óleo e gás em função das particularidades das mesmas (as transações dificilmente são comparáveis dado que cada 
reservatório possui características próprias, bem como não existe um mercado ativo capaz de estabelecer o custo de reposição de uma reserva de óleo e gás), restando como critério à abordagem do fluxo de caixa descontado que, nesse caso, diversas premissas seriam requeridas, tais como: (a) interpretação geológica do reservatório de óleo e gás, incluindo a estimativa das quantidades (e qualidade) de petróleo existente no reservatório; (b) suposições sobre fatores técnicos que determinaram as estimativas das quantidades de óleo e gás existente no reservatório e que poderiam ser extraídas do mesmo, incluindo as taxas de pressão e fluxo do reservatório; (c) perfil da produção sobre a vida útil do reservatório; (d) preço do petróleo; taxas de câmbio; custos de desenvolvimento e de produção; impostos, royalties e outros pagamentos ao governo aplicáveis sobre a vida útil do reservatório; e (e) taxa de desconto relacionado ao valor do dinheiro no tempo e aos riscos ainda não refletidos na estimativa do fluxo de caixa futuro (IASB, 2010a).

A questão em relação à abordagem do fluxo de caixa futuro descontado diz respeito ao fato de que muitas dessas premissas estão associadas a elevados níveis de incerteza ou a falta de dados de mercado observáveis. Essas incertezas são extremante elevadas durante a fase inicial de um projeto exploratório, onde o conhecimento sobre a existência ou se os recursos encontrados poderão ser economicamente produtivos é insuficiente, fazendo com que qualquer estimativa de quantidade ou custo para se produzir seja subjetiva ou mesmo especulativa (IASB, 2010a).

Dada a complexidade apresentada para a utilização do valor justo como base de mensuração dos ativos de óleo e gás, o grupo de trabalho também analisou o custo histórico como base de valor. Consideraram que o custo histórico dos ativos de óleo e gás geralmente só fornece informação relevante para se avaliar os fluxos de caixa futuros quando ele é igual ao valor justo. E isso ocorre normalmente nas transações de compra e venda de direitos exploratórios (IASB, 2010a).

Contudo, a relevância do custo histórico vai diminuindo e se distanciando do valor justo quando mais informações sobre o reservatório (estimativa do tamanho, qualidade e recuperabilidade econômica) estão disponíveis. Como resultado, o custo histórico da exploração não seria relevante para se avaliar os fluxos de caixa futuros em função de ele não se correlacionar com o fluxo de caixa que poderá ser gerado pela produção de óleo e gás do reservatório (IASB, 2010a).

A visão prevalecente, principalmente levando-se em conta o custo-benefício da informação, foi a de que tanto o valor histórico quanto o valor justo fornecem informações limitadas, e a proposta encontrada é a de que os ativos deveriam ser mensurados com base no valor histórico e que informações complementares seriam exigidas em notas explicativas às demonstrações financeiras para permitir que os usuários pudessem utilizar essas informações em seus modelos proprietários de avaliação de empresas (Nichols, 2009).

Dessa forma, o DPEA trouxe para discussão a seguinte questão norteadora: Questão 6 - Você concorda que os ativos minerais ou de óleo e gás devem ser mensurados com base no custo histórico e que informações adicionais devem ser detalhadamente divulgadas com o objetivo de fornecer uma maior relevância às demonstrações financeiras?

O resultado da audiência pública aponta que, conforme Santos e Santos (2014), quase a totalidade dos respondentes (94 respostas, das 100 submetidas a essa questão) concordou com a proposta oferecida pelo grupo de trabalho em prol do custo histórico em função de ser um valor verificável, de fácil preparação (rapidez/disponibilidade) e usado para avaliar o desempenho e a gestão da empresa. Os respondentes dessa questão do DPEA não concordaram com a adoção do valor justo em função de que seria introduzida nas demonstrações financeiras uma subjetividade excessiva e alta volatilidade de curto prazo, além de que imporia significativos custos de preparação e de auditoria das demons- 
trações financeiras, não se justificando em relação aos benefícios possivelmente gerados aos usuários das informações (IASB, 2010b).

\subsection{DIVULGAÇÃO OBRIGATÓRIA}

A regulação da contabilidade apresenta diversos motivos, sendo que boa parte deles referem-se à redução da assimetria informacional, proteção dos pequenos investidores (menos informados) e padronização das informações (transparência e comparabilidade) (Lev, 1988; Beaver, 1998 E Chung, 1999).

Murcia e Santos (2009) argumentam que a função da regulação é gerar comprometimento por parte da empresa, uma vez que lhe obriga a divulgar informações em tempos bons ou ruins, ou seja, é uma forma de forçar a divulgação de informações mesmo quando isso trouxer mais malefícios do que benefícios. A conclusão é a de que as empresas não estariam dispostas a aumentar o nível de divulgação de suas informações, a não ser quando obrigadas.

No que se referem às divulgações obrigatórias das empresas petrolíferas, as discussões giram em torno de quais informações, contábeis e não contábeis, seriam úteis ao público de interesse dessas empresas. Nas decisões econômicas sobre as empresas do setor extrativista, os usuários necessitam essencialmente de informações sobre os fluxos de caixas provenientes das reservas minerais ou de óleo e gás. Informações sobre as reservas também são relevantes para determinar se os gestores têm sido eficientes no uso dos recursos que lhes foi confiado.

Dada a relevância limitada que os usuários atribuem ao reconhecimento e mensuração dos ativos de óleo e gás nas demonstrações financeiras, o objetivo da divulgação das atividades extrativistas deve focar no fornecimento de informações adicionais sobre esses ativos que sejam úteis à tomada de decisões e avaliação dos gestores na administração da empresa (IASB, 2010a).

Na opinião do time do projeto do DPEA, expresso na $8^{a}$ questão, o objetivo da divulgação para atividades extrativistas é fornecer informações adicionais que possam permitir aos usuários avaliar: (a) o valor atribuível aos ativos minerários ou de óleo e gás de uma entidade; (b) a contribuição desses ativos para o desempenho do período corrente; e (c) a natureza e extensão dos riscos e incertezas associadas a esses ativos (IASB, 2010a).

Para atender a esses objetivos, a divulgação pode ser resultante de uma exigência regulatória ou de ações voluntárias dado que algumas entidades veem esses objetivos como melhor prática, principalmente em função de que, em algumas jurisdições, são exigidas pelo regulador do mercado de capitais e não por uma norma contábil. O time do projeto não concorda que as informações relevantes das atividades extrativistas tenham caráter voluntário ou exigido por outros meios que não uma norma contábil, uma vez que as informações sobre as reservas seriam o ponto chave das demonstrações financeiras das empresas desse setor (IASB, 2010a).

Quanto às informações que seriam úteis na avaliação do desempenho corrente de uma empresa do setor extrativista, poderia se incluir informações sobre: (a) receitas de venda dos minerais ou óleo e gás e os respectivos custos de produção; (b) gastos exploratórios, de avaliação e de desenvolvimento reconhecidos como despesas no resultado; e (c) gastos exploratórios, de avaliação e de desenvolvimento que foram ativados. Informações não financeiras também contribuem para a avaliação do desempenho da empresa, tais como a quantidade de reservas de óleo e gás produzidas no período, novas descobertas realizadas e as mudanças ocorridas na estimativa da quantidade de reservas. 
Além disso, as empresas deveriam fornecer informações suficientes sobre a natureza e extensão dos riscos e incertezas associados aos ativos minerários ou de óleo e gás, como: (a) expressar as estimativas das quantidades recuperáveis de óleo e gás em diferentes intervalos de confiança; (b) apresentar separadamente essas estimativas por ativos sujeitos a diferentes riscos, como os riscos de mercado e o risco político; (c) divulgar as suposições assumidas nas estimativas e uma análise de sensibilidade dessas suposições; e (d) explicações sobre as mudanças ocorridas nas estimativas ano a ano.

Tomando como base as exigências contidas no SFAS 69, as diferenças da proposta do DPEA são pequenas, mas relevantes, a não ser no cenário da adoção da mensuração a valor justo. A primeira diferença refere-se à obrigatoriedade de divulgação das reservas prováveis, pois o time do projeto entende que as decisões gerenciais levam em contam também essa categoria de reserva e não apenas as reservas provadas. Argumentos contrários à divulgação das reservas prováveis dão conta de que os usuários podem se iludir se eles não compreenderem os riscos e incertezas associados às estimativas dessa categoria de reserva, possibilitando, inclusive, riscos de litígios.

Também se exigiria a divulgação dos métodos e principais premissas utilizadas. No último caso, a proposta contida no DPEA vai de encontro ao SFAS 69 quando o assunto refere-se à premissa preço $\mathrm{e}$ taxa de desconto. O SFAS 69 determina que o preço para a estimativa das receitas futuras seja a média do preço do barril negociado nos últimos doze meses e para a estimativa dos custos, o valor corrente. O DPEA coloca como possibilidade a utilização de um preço médio histórico ou o preço corrente de mercado para as receitas. Para os custos e despesas não há diferenças. Quanto à taxa de desconto, o SFAS 69 prega a utilização da taxa de 10\% ao ano, enquanto que o DPEA direciona para a utilização de uma taxa representada pelo custo médio ponderado de capital da empresa.

Contudo, a exigência quanto à divulgação de uma análise de sensibilidade das premissas utilizadas corresponde, na opinião de Nichols (2009), a principal mudança quanto às informações complementares. Em função da grande quantidade de suposições econômicas que são feitas, a autora considera que a divulgação da análise de sensibilidade de forma detalhada só será viável nos casos em que a premissa utilizada não causar mudanças em outras premissas. Caso contrário, a complexidade será elevada (Nichols, 2009).

Nesse contexto, o DPEA traz para discussão, além da 8a questão já apresentada, a seguinte indagação relacionada à divulgação das informações de empresas do setor extrativista:

Questão 9 - Você concorda que as informações que devem ser divulgadas em notas explicativas às demonstrações financeiras devem incluir: (a) a quantidade de reservas provadas mais as reservas provadas e prováveis, com divulgação das quantidades de reservas separadamente por commodity e área geográfica material; (b) as principais premissas utilizadas para estimar as quantidades de reservas e uma análise de sensibilidade; (c) uma reconciliação entre as mudanças de estimativas nas quantidades de reservas de um ano para outro; (d) uma mensuração a valores correntes das quantidades de reservas divulgadas e uma reconciliação em relação às mudanças ocorridas; (e) identificação separada dos fluxos de caixas da exploração, desenvolvimento e operações do período corrente em uma série de tempo, como por exemplo, de cinco anos; e (f) identificação separada das receitas de produção por commodity?

Russell e Jenkins (2010) analisam que a divulgação de mais informações sobre as reservas parece ser um desejo dos usuários, mas que a proposta apresentada no DPEA, na opinião dos autores, não representa uma melhoria significativa sobre as exigências atuais do setor, como aquelas imposta pela norma SFAS 69 e que já foram objeto de diversas pesquisas, a saber: 


\begin{tabular}{|c|c|c|}
\hline Pesquisa & Objetivo & Resultados \\
\hline Clinch e Magliolo (1992) & $\begin{array}{l}\text { Investigar se a divulgação das quantidades das } \\
\text { reservas provadas totais, reservas provadas } \\
\text { desenvolvidas e a quantidade relativa à } \\
\text { produção, conforma as exigências do SFAS } 69, \\
\text { possuíam conteúdo informacional. }\end{array}$ & $\begin{array}{l}\text { As evidências sugerem que apenas as quantidades extraídas das } \\
\text { reservas de óleo e gás (produção) apresentam relevância para } \\
\text { o mercado de capitais. Depreende-se que a informatividade da } \\
\text { divulgação das reservas exigidas pelo SFAS } 69 \text { varia de acordo } \\
\text { com a confiança nas projeções realizadas. Como a quantidade } \\
\text { produzida é um dado real, essa informação é mais objetiva } \\
\text { para os investidores, enquanto que as quantidades de reservas } \\
\text { provadas totais e desenvolvida são apenas estimativas. }\end{array}$ \\
\hline Alciatore (1993) & $\begin{array}{l}\text { Investigar a relevância das informações sobre } \\
\text { reservas, tendo por base dez itens divulgáveis } \\
\text { relacionadas ao processo de estimativa das } \\
\text { reservas petroliferas. }\end{array}$ & $\begin{array}{l}\text { As informações relativas às quantidades produzidas; quantidades } \\
\text { descobertas no período; quantidades de reservas vendidas; } \\
\text { mudanças decorrentes das estimativas do período anterior; } \\
\text { mudanças nos preços do barril utilizado nas estimativas; e } \\
\text { mudanças na alíquota do imposto sobre lucro, possuem poder } \\
\text { informacional incremental quando comparado com outros } \\
\text { componentes exigidos pelo SFAS } 69 \text { e o lucro líquido. }\end{array}$ \\
\hline Spear (1996) & $\begin{array}{c}\text { Identificar se o retorno não esperado das } \\
\text { ações pode ser explicado pelas informações } \\
\text { derivadas das reservas, que foram sumarizadas } \\
\text { em três variáveis. }\end{array}$ & $\begin{array}{l}\text { Os resultados indicam que as descobertas de novas reservas e } \\
\text { as revisões das estimativas do período anterior possuem poder } \\
\text { informativo incremental, o mesmo não ocorrendo com as } \\
\text { variaçöes líquidas no valor padronizado das reservas. }\end{array}$ \\
\hline Berry, Hasan e O'Bryan (1998) & $\begin{array}{l}\text { Identificar, utilizando-se o modelo de Ohlson } \\
\text { (1995), se a informação do valor padronizado } \\
\text { das reservas provadas é mais relevante do } \\
\text { que as quantidades estimadas dessas mesmas } \\
\text { reservas. }\end{array}$ & $\begin{array}{l}\text { Tanto o valor das reservas quanto a quantidade estimada das } \\
\text { mesmas mostraram-se relevantes, mas não foi possível confirmar } \\
\text { a superioridade de uma informação sobre a outra. }\end{array}$ \\
\hline Boone, Luther e Raman (1998) & $\begin{array}{l}\text { Investigaram o efeito da divulgação da } \\
\text { quantidade das reservas não provadas (o } \\
\text { que não é exigido pelo SFAS } 69 \text { no caso de } \\
\text { empresas norte-americanas, mas obrigatório } \\
\text { em alguns países) sobre o bid-ask spread. }\end{array}$ & $\begin{array}{l}\text { Os resultados indicaram que a divulgação dessa informação } \\
\text { melhora potencialmente a qualidade do mercado, ocasionando a } \\
\text { redução da assimetria informacional, em aderência aos achados } \\
\text { de Raman e Tripathy (1993). }\end{array}$ \\
\hline Boynton IV, Boone e Coe (1999) & $\begin{array}{l}\text { Avaliar a utilidade das informações sobre os } \\
\text { custos de descoberta (finding costs) como } \\
\text { indicador da eficiência exploratória e do } \\
\text { potencial de lucratividade da empresa. }\end{array}$ & $\begin{array}{c}\text { Os resultados sugerem que os custos de descoberta calculados } \\
\text { com base nas informações disponibilizadas pelo SFAS } 69 \\
\text { possuem relevância estatística quanto à sua utilidade para } \\
\text { avaliar a eficiência exploratória e do potencial de lucratividade } \\
\text { da empresa. }\end{array}$ \\
\hline Berry e Wright (2001) & $\begin{array}{l}\text { Avaliar a relevância das informações } \\
\text { relacionadas ao esforço e habilidade das } \\
\text { empresas em descobrirem novas reservas de } \\
\text { óleo e gás. }\end{array}$ & $\begin{array}{l}\text { Os resultados mostraram que a intensidade exploratória (esforço) } \\
\text { é percebida pelo mercado de capitais, sendo relevante para } \\
\text { explicar o comportamento do preço das ações, enquanto que o } \\
\text { fator habilidade só foi relevante para a amostra com empresas } \\
\text { full cost. }\end{array}$ \\
\hline
\end{tabular}

Como se nota, no Quadro 1, os resultados empíricos apresentam uma miscelânea de resultados que ainda não são capazes de evidenciar, de fato, que as informações complementares atualmente exigidas das empresas petrolíferas sejam úteis para tomada de decisão por parte dos usuários das demonstrações financeiras. Isso implica em maior complexidade ao normatizador em sua tarefa de emitir normas contábeis que permitam a elaboração de informações de alta qualidade.

Ao se considerar os comentários recebidos pelo IASB às questões 8 e 9 do DPEA, corrobora-se essa difícil tarefa do normatizador. Conforme Santos e Santos (2014), a maioria dos respondentes suportou os objetivos gerais relacionados à divulgação obrigatória de informações complementares, mas foram amplamente desfavoráveis à proposta quanto aos itens que teriam divulgação obrigatória.

Seguindo o pressuposto de Lev (1988), de que não se sabe com precisão que informações são efetivamente relevantes para os usuários, é necessário encontrar respostas que possam colaborar com esse desafio dos emissores de normas contábeis. Para tanto, testes empíricos são realizados neste estudo com esse objetivo, trazendo novas e mais recentes evidências. 


\section{METODOLOGIA}

Trata-se de um estudo quantitativo, cuja operacionalização se dá por meio da utilização da análise de regressão com dados em painel, cuja abordagem mais apropriada é decidida com base nos testes estatísticos de Chow, de Breusch-Pagan e de Hausman.

Como as questões trazidas à discussão pelo DPEA orbitam em torno da relevância das informações contábeis quanto ao atendimento das necessidades dos usuários da informação no processo de tomada de decisões econômicas, utiliza-se de modelos baseados no trabalho de Collins, Maydew e Weiss (1997) para fornecer evidências empíricas sobre as questões em debate no DPEA, cuja especificação genérica pode ser dada por:

Valor da Empresa ${ }_{i t}=f\left(\right.$ Variáveis Contábeis $_{i t}$; Variáveis não Contábeis ${ }_{\mathrm{it}}$ )

A investigação acadêmica da relação entre a reação do mercado de capitais e uma informação contábil específica é conhecida como value relevance, de acordo com Holthausen e Watts (2001). Os autores apresentam três possíveis interpretações para a abordagem de pesquisas sobre o "valor relevante": estudos de associação relativa; estudos de associação incremental; e estudos de conteúdo informacional marginal. O estudo desenvolvido pode ser enquadrado como estudo de associação incremental.

De acordo com Brown, Lo e Lys (1999), nesse tipo de estudo, normalmente são aplicados análises de regressão, tendo como variável dependente uma proxy relacionada ao preço das ações e como variáveis independentes, proxies relacionadas às informações contábeis e não contábeis.

\subsection{DEFINIÇÃO DAS VARIÁVEIS E HIPÓTESES DE PESQUISA}

As variáveis de interesse foram selecionadas visando à confirmação ou não da relevância do custo histórico e das informações complementares atualmente divulgadas pelas empresas e que possivelmente farão parte das exigências de uma futura IFRS.

\subsubsection{Proxies para o Custo Histórico}

No caso do conjunto disponibilizado de informações que retratam o custo histórico, têm-se as seguintes variáveis.

\begin{tabular}{|c|c|c|}
\hline Variáveis Independentes & $\begin{array}{l}\text { Descrição e Utilização em } \\
\text { Estudos Anteriores }\end{array}$ & $\begin{array}{c}\text { Fundamentação contida no } \\
\text { DPEA }\end{array}$ \\
\hline $\begin{array}{l}\text { Ativos de Exploração e Produção } \\
\text { (ATIVOE\&P) }\end{array}$ & $\begin{array}{c}\text { Total dos ativos identificados com o segmento } \\
\text { de exploração e produção de óleo e gás. } \\
\text { Essa variável é impactada pelo método de } \\
\text { contabilização utilizado: successful efforts ou } \\
\text { full cost. } \\
\text { Harris e Ohlson (1987); Chung, Ghicas e } \\
\text { Pastena (1993); Boone e Raman (2007) e } \\
\text { Asekomeh et al (2010). }\end{array}$ & $\begin{array}{l}\text { Os gastos incorridos para se encontrar reservatórios minerais } \\
\text { e de óleo e gás (ativados) não geram informações úteis aos } \\
\text { usuários para predizerem fluxos de caixa futuros provenientes } \\
\text { dos ativos vinculados aos reservatórios. }\end{array}$ \\
\hline $\begin{array}{l}\text { Gastos Totais (CAPEX), Gastos } \\
\text { Exploratórios (GEXPLO) e Gastos } \\
\text { de Desenvolvimento (GDESEN) }\end{array}$ & $\begin{array}{c}\text { Total dos ativos identificados com o segmento } \\
\text { de exploração e produção de óleo e gás. } \\
\text { Essa variável é impactada pelo método de } \\
\text { contabilização utilizado: successful efforts ou } \\
\text { full cost. } \\
\text { Harris e Ohlson (1987); Chung, Ghicas e } \\
\text { Pastena (1993); Boone e Raman (2007) e } \\
\text { Asekomeh et al (2010). }\end{array}$ & $\begin{array}{c}\text { Alguns usuários consultados pelo grupo de trabalho do IASB } \\
\text { apontaram para a utilidade de tais variáveis, indicando que as } \\
\text { mesmas são relevantes em seu processo decisório. }\end{array}$ \\
\hline
\end{tabular}




\begin{tabular}{|c|c|c|}
\hline $\begin{array}{l}\text { Lucro Líquido do Segmento } \\
\text { de Exploração e Produção } \\
\text { (LUCROSEG) }\end{array}$ & $\begin{array}{l}\text { Lucro líquido obtido exclusivamente pelo } \\
\text { segmento de exploração e produção. } \\
\text { Amir e Lev (1996); Collins, Maydew e Weiss } \\
\text { (1997); Aboody e Lev (1998); Brown, Lo e Lys } \\
\text { (1999); Barth, Landsman e Lang (2008); Lopes } \\
\text { (2001) e Santos e Silva (2014). }\end{array}$ & $\begin{array}{l}\text { Atender ao item "b" da } 8^{a} \text { questão (contribuição dos ativos de } \\
\text { óleo e gás para o desempenho financeiro do período corrente) e, } \\
\text { de certa forma, ao item "f" da 9a questão (identificação separada } \\
\text { das receitas de produção por commodity). }\end{array}$ \\
\hline $\begin{array}{l}\text { Variação do Lucro Líquido } \\
\text { (VLUCROLIQ) }\end{array}$ & 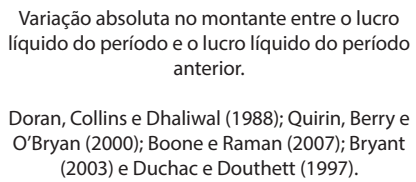 & $\begin{array}{l}\text { Usuários consultados indicam que estariam mais interessados } \\
\text { nas variações que ocorrem de um período para o outro ao invés } \\
\text { da informação propriamente dita. }\end{array}$ \\
\hline
\end{tabular}

Fonte: elaboração própria

As variáveis contábeis mensuradas com base no custo histórico selecionadas mantém relação com algum argumento e/ou questionamento apresentado pelo IASB em seu DPEA. Trabalhos anteriores estudaram essas variáveis em vários prismas. Ao se considerar tais variáveis em um modelo econométrico único, espera-se fornecer evidências ao IASB quanto aos seus argumentos e/ou questionamentos, tendo como parâmetro a seguinte hipótese de pesquisa:

H1: As informações complementares divulgadas pelas empresas petroliferas baseadas em variáveis contábeis mensuradas a custos históricos são relevantes para a avaliação dos preços das ações.

A não rejeição dessa hipótese implica em considerar que a posição do IASB em favor do custo histórico como parâmetro para mensuração dos eventos econômicos relacionados às empresas petrolíferas encontra respaldo empírico para se argumentar que as informações apresentam relevância para os usuários da informação, premissa fundamental das normas contábeis internacionais

\subsection{PROXIES PARA DIVULGAÇÃO}

No caso do conjunto de informações atualmente divulgadas, grandemente baseadas nas exigências contidas no SFAS 69 e não relacionadas a variáveis contábeis, têm-se as seguintes variáveis:

Quadro 3: Variáveis Independentes Divulgação

\begin{tabular}{|c|c|c|}
\hline Variáveis Independentes & $\begin{array}{c}\text { Descrição e Utilização em Estudos } \\
\text { Anteriores }\end{array}$ & $\begin{array}{c}\text { Fundamentação contida no } \\
\text { DPEA }\end{array}$ \\
\hline $\begin{array}{l}\text { Custo da Descoberta por barril } \\
\text { (FINDCOST) }\end{array}$ & $\begin{array}{c}\text { Montante gasto por barril para adquirir, } \\
\text { explorar e desenvolver reservas, incluindo } \\
\text { novas descobertas, aquisições e revisões } \\
\text { das reservas anteriormente estimadas. É } \\
\text { calculado pela razão entre o total dos gastos } \\
\text { exploratórios do período e a quantidade de } \\
\text { reservas estimadas do período. } \\
\text { Boynton IV, Boone e Coe (1999); Quirin, Berry e } \\
\text { O'Bryan (2000) e Misund, Asche e Osmundsen } \\
\text { (2008). }\end{array}$ & $\begin{array}{c}\text { O custo da descoberta é apresentado no DPEA como uma das } \\
\text { poucas informações complementares divulgadas pelas empresas } \\
\text { de óleo e gás como relevante, sendo que sua utilidade reside } \\
\text { na avaliação da habilidade da empresa em encontrar óleo e gás } \\
\text { eficientemente. }\end{array}$ \\
\hline $\begin{array}{c}\text { Taxa de Sucesso Exploratório } \\
\text { (TAXASUC) }\end{array}$ & $\begin{array}{l}\text { Indica, para o total de poços perfurados no } \\
\text { período, o percentual daqueles em que se } \\
\text { obteve sucesso, ou seja, que se descobriu } \\
\text { óleo ou gás. É um indicador de eficiência } \\
\text { operacional e mostra a capacidade de a } \\
\text { empresa em encontrar petróleo. } \\
\text { Lilien e Pastena (1982); Wright e Gallun (2008) } \\
\text { e Santos, Santos e Silva (2011). }\end{array}$ & $\begin{array}{c}\text { A taxa de sucesso exploratório é comumente utilizada como } \\
\text { proxy para o risco exploratório e, portanto, atende, de certa } \\
\text { forma, ao item "c" da 8a questão (riscos e incertezas associados } \\
\text { aos ativos). }\end{array}$ \\
\hline $\begin{array}{l}\text { Quantidade de Reservas Provadas } \\
\text { e Variação (QTRESPROV e } \\
\text { VQTRESPROV) }\end{array}$ & $\begin{array}{l}\text { Quantidade de óleo e gás estimada e definida } \\
\text { como reserva provada, ou seja, a quantidade } \\
\text { de óleo e gás que podem ser recuperadas } \\
\text { comercialmente. } \\
\text { Clinch e Magliolo (1992); Berry, Hasan e } \\
\text { O'Bryan (1998); Berry e Wright (2001) e Misund, } \\
\text { Osmundsen e Asche (2005). }\end{array}$ & $\begin{array}{c}\text { O DPEA aponta que a informação da quantidade de reservas é } \\
\text { um input importante para os usuários estimarem o valor dos } \\
\text { ativos de óleo e gás e os fluxos de caixa futuros gerados por } \\
\text { esses ativos. }\end{array}$ \\
\hline
\end{tabular}




\begin{tabular}{|c|c|c|}
\hline $\begin{array}{l}\text { Fluxo de Caixa Descontado } \\
\text { Padronizado das Reservas (FCDP) }\end{array}$ & $\begin{array}{l}\text { Valor presente dos fluxos de caixas futuros } \\
\text { provenientes das reservas provadas da } \\
\text { empresa, sendo uma aproximação do "valor } \\
\text { justo" dos ativos de óleo e gás. Baseia-se em } \\
\text { premissas padronizadas: preço de venda } \\
\text { correspondente ao preço médio do petróleo } \\
\text { negociado durante o período; custos } \\
\text { estimados com base nos valores correntes do } \\
\text { final do período e taxa de desconto de 10\% } \\
\text { ao ano. } \\
\text { Doran, Collins e Dhaliwal (1988); Chung, Ghicas } \\
\text { e Pastena (1993); Raman e Tripathy (1993); } \\
\text { Alciatore (1993); Spear (1996); Berry, Hasan e } \\
\text { O'Bryan (1998); Wright e Brock (1999); Bryant } \\
\text { (2003); Santos, Santos e Silva (2011) e Santos } \\
\text { e Silva (2014). }\end{array}$ & $\begin{array}{l}\text { O DPEA apresenta severas críticas à mensuração padronizada do } \\
\text { valor das reservas por não ser um valor real da estimativa futura } \\
\text { de fluxos de caixa da empresa; em última instância, a informação } \\
\text { mais desejada pelos usuários da informação contábil em seu } \\
\text { processo decisório. }\end{array}$ \\
\hline
\end{tabular}

Fonte: elaboração própria

Tendo em vista o conjunto de variáveis não contábeis e divulgadas atualmente pelas empresas, tem-se a seguinte hipótese de pesquisa:

H2: As informações complementares divulgadas atualmente pelas empresas petrolíferas e baseadas em variáveis não contábeis são relevantes para a avaliação dos preços das ações.

A não rejeição dessa hipótese implica em considerar que a posição do IASB em aumentar o nível de divulgação obrigatória por parte das empresas pode encontrar resistência para a sua implementação, dado que se terá respaldo empírico para se argumentar que o atual nível de divulgação já atende as necessidades usuários da informação, tendo em vista sua capacidade informacional.

\subsubsection{Especificação dos Modelos Econométricos}

Baseado no trabalho de Collins, Maydew e Weiss (1997), têm-se os seguintes modelos econométricos, nos quais o valor da empresa (medido pelo preço de suas ações) é função de variáveis contábeis e não contábeis.

Modelo com variáveis contábeis (custo histórico):

$$
\begin{aligned}
& \text { PREÇO } O_{i t+3}=\alpha+\beta_{1} \cdot L P A_{i t}+\beta_{2} \cdot P L A_{i t}+\beta_{3} \cdot A T I V O E \& P_{i t}+\beta_{4} \cdot V L U C R O L I Q_{i t} \\
& +\beta_{5} \cdot \text { CAPEX }_{i t}+\beta_{6} \cdot \text { GEXPLO }_{i t}+\beta_{7} \cdot \text { GDESEN }_{i t}+\beta_{8} \cdot \text { LUCROSEG }_{i t}+\varepsilon_{i t}
\end{aligned}
$$

Modelo com variáveis não contábeis (divulgações realizadas):

$$
\begin{aligned}
& P P E C \zeta O_{i t+3}=\alpha+\omega_{1} \cdot L P A_{i t}+\omega_{2} \cdot P L A_{i t}-\omega_{3} \cdot F I N D C O S T_{t t}+\omega_{4} \cdot T A X A S U C_{i t} \\
& +\omega_{\xi} \cdot \text { QTRESPROV Vit }+\omega_{6} \cdot V Q T R E S P R O V_{i t}+\omega_{7} \cdot F C D P_{i t}+\varepsilon_{i t}
\end{aligned}
$$

Em que, além das variáveis já especificadas anteriormente nos quadros 2 e 3, têm-se:

$\mathrm{PREÇO}_{\mathrm{it+3}}$ é o preço das ações, ajustadas pelos dividendos e desdobramentos, da empresa i no período $\mathrm{t}+3$ (três meses após o fim do ano anterior);

$\mathrm{LPA}_{\text {it }}$ é o lucro líquido por ação da empresa i no final do período t;

$P L A_{i t}$ é o patrimônio líquido por ação da empresa i no final do período t;

a é o intercepto e o termo de erro da regressão da empresa i no período t;

$\beta 1, \beta 2, \ldots, \beta 8$ e $\omega 1, \omega 2, \ldots, \omega 7$ são os coeficientes estimados, de onde se espera que sejam positivos e estatisticamente significantes, à exceção de $\omega 3$, que se espera apresentar sinal negativo, ou seja, quanto menores os custos para se descobrir novas reservas, maior a expectativa de bons resultados, uma vez que o FINDCOST é um indicador que retrata a habilidade de a empresa em descobrir petróleo de forma eficiente, conforme argumentos de Wrigth e Gallun (2008). 
Os pressupostos da regressão foram observados, adotando-se medidas corretivas, tais como: eliminação das informações atípicas (outliers); transformação de variáveis (logaritmo natural); ou correções disponibilizadas pelos softwares estatísticos (coeficiente de covariância consistente de Newey-West - para heterocedasticidade e autocorrelação).

\subsection{PLANO AMOSTRAL}

Utiliza-se a base de dados da Evaluate Energy ${ }^{\oplus}$, compreendendo informações de 143 empresas, do período de 2005 a 2011. Considerando a variável dependente (preço), a base de dados continha essa informação para 138 empresas, considerando todos os anos da amostra, perfazendo um total de 966 observações, que é a amostra base para a realização dos testes, conforme Tabela 1.

Tabela 1: Planos Amostrais

\begin{tabular}{|c|c|}
\hline $\begin{array}{c}\text { Informações brutas disponíveis na base da Evaluate Energy } \\
\text { (143 empresas } x \text { 7 anos) }\end{array}$ & 1.001 \\
$(-)$ Dados faltantes para variável dependente PREÇO & $(35)$ \\
= Amostra base para o teste (138 empresas x 7 anos) & 966 \\
\hline Plano Amostral - Custo Histórico & 966 \\
Amostra base para o teste & $(407)$ \\
(-) Dados faltantes \\
$=$ Amostra utilizada & 559 \\
\hline Plano Amostral - Divulgação Obrigatória & 966 \\
Amostra base para o teste \\
(-) Dados faltantes \\
$=$ Amostra utilizada & $(597)$ \\
\hline
\end{tabular}

Fonte: elaboração própria.

Contudo, em decorrência de dados faltantes de algumas variáveis independentes, a amostra final utilizada na investigação da relevância das informações a valores históricos foi de 559 observações, enquanto que para os testes sobre a divulgação de informações obrigatórias, de 369 observações.

\subsection{ESCOLHA DOS MODELOS DE DADOS EM PAINEL}

Realizaram-se testes estatísticos para definir a melhor abordagem em cada uma das duas dimensões propostas conforme especificado no Quadro 4.

Quadro 4: Escolha da Abordagem para Dados em Painel

\begin{tabular}{|c|c|c|c|}
\hline Teste Estatístico & Hipótese de Teste & p-valor & $\begin{array}{c}\text { Conclusão } \\
\text { Custos Históricos }\end{array}$ \\
\hline Chow & $\begin{array}{c}\text { HO: Efeito Combinado } \\
\text { H1: Efeitos Fixos }\end{array}$ & 0,000 & Efeitos Fixos \\
\hline Breusch-Pagan & $\begin{array}{l}\text { HO: Efeito Combinado } \\
\text { H1: Efeitos Aleatórios }\end{array}$ & 0,000 & Efeitos Aleatórios \\
\hline Hausman & $\begin{array}{c}\text { H0: Efeitos Aleatórios } \\
\text { H1: Efeitos Fixos }\end{array}$ & 0,000 & Efeitos Fixos \\
\hline \multicolumn{4}{|c|}{ Abordagem utilizada: Efeitos Fixos } \\
\hline Teste Estatístico & Hipótese de Teste & p-valor & $\begin{array}{c}\text { Conclusão } \\
\text { Divulgaçōes Realizadas }\end{array}$ \\
\hline Chow & $\begin{array}{c}\text { HO: Efeito Combinado } \\
\text { H1: Efeitos Fixos }\end{array}$ & 0,000 & Efeitos Fixos \\
\hline Breusch-Pagan & $\begin{array}{l}\text { HO: Efeito Combinado } \\
\text { H1: Efeitos Aleatórios }\end{array}$ & 0,000 & Efeitos Aleatórios \\
\hline Hausman & $\begin{array}{c}\text { H0: Efeitos Aleatórios } \\
\text { H1: Efeitos Fixos }\end{array}$ & 0,017 & Efeitos Fixos \\
\hline
\end{tabular}

Fonte: dados da pesquisa. 
A decisão pela utilização da regressão com dados em painel decorre do fato desta possibilitar reduzir os problemas de multicolinearidade das variáveis explicativas; proporcionar dados mais informativos; permitir maior controle sobre a heterogeneidade e melhor inferência dos parâmetros estimados (Gujarati \& Porter, 2011).

$\mathrm{Na}$ abordagem dos efeitos fixos, as alterações nas cross-section ao longo do tempo são levadas em consideração. O modelo sugere que o intercepto das observações (empresas) pode ser diferente, e essa diferença pode ser devida às características peculiares de cada observação. Assim, o pressuposto do modelo é de que, embora o intercepto possa diferir entre indivíduos, cada intercepto individual não se altera ao longo do tempo.

\section{RESULTADOS}

A Tabela 2 contém a estatística descritiva das variáveis selecionadas para os testes econométricos.

Tabela 2: Estatística Descritiva

\begin{tabular}{c|c|c|c|c|c}
\hline VARIÁVEL & MÉDIA & MEDIANA & MÍNIMO & MÁXIMO & $\begin{array}{c}\text { DESVIO } \\
\text { PADRÃO }\end{array}$ \\
\hline PREÇO & 25,09 & 14,08 & 0,01 & $1.133,74$ & 47,84 \\
\hline LPA & 1,26 & 0,81 & $-195,65$ & 15,00 & 7,78 \\
\hline PLA & 13,32 & 6,89 & $-6,12$ & 718,38 & 30,75 \\
\hline ATIVOE\&P & $15.173,60$ & $2.275,50$ & 2,00 & $301.873,00$ & $33.189,50$ \\
\hline LUCROSEG & $2.675,75$ & 276,12 & $-15.455,00$ & $48.948,90$ & $6.654,68$ \\
\hline VLUCRO & 205,83 & 9,20 & $-28.240,00$ & $29.419,00$ & $2.533,30$ \\
\hline CAPEX & $2.863,31$ & 465,36 & 0,01 & $43.878,70$ & $6.197,46$ \\
\hline GEXPLO & 571,99 & 147,00 & 0,00 & $6.461,00$ & 956,78 \\
\hline GDESEN & $2.324,51$ & 631,00 & 0,00 & $24.538,00$ & $3.766,98$ \\
\hline QTRESPROV & $3.383,81$ & 325,27 & 0,01 & $122.702,00$ & $12.399,40$ \\
\hline VQTRESPROV & 88,60 & 5,97 & $-2.096,17$ & $13.682,50$ & 653,46 \\
\hline FTCDP & $19.390,20$ & $3.443,50$ & 0,10 & $271.220,00$ & $38.918,20$ \\
\hline FAXASUC & 0,68 & 0,75 & 0,00 & 1,00 & 0,30 \\
\hline FINDCOST & 21,31 & 5,60 & $-662,07$ & $1.644,35$ & 114,06 \\
\hline
\end{tabular}

Fonte: dados da pesquisa. Nota: PREÇO: preço das ações em t mais 3 meses, ajustado pelos dividendos e desdobramentos; LPA: lucro líquido por ação; PLA: patrimônio líquido por ação: ATIVOE\&P: total dos ativos do segmento de exploração e produção; LUCROSEG; lucro líquido do segmento de exploração e produção; VLU CRO: variação anual do lucro líquido; CAPEX: total dos gastos incorridos nos projetos de exploração e produção; GEXPLO: total dos gastos incorridos na fase de exploração do projeto; GDESEN: total dos gastos incorridos na fase de desenvolvimento do projeto; QTRESPROV: volume de reservas provadas; VQRESPROV: variação anual no volume de reservas provadas; FCDP: fluxo de caixa descontado padronizado decorrente das reservas; TAXASUC: taxa de sucesso exploratório; FINDCOST: custo da descoberta por barril.

Como pode ser observada, a amostra se caracteriza por conter empresas de diferentes tamanhos, como por exemplo, grandes petrolíferas com mais de US\$300 bilhões em ativos do segmente de exploração e produção, ou petrolíferas com apenas US\$ 2 milhões. Esse fato implica que os desvios padrões sejam elevados e indicam também possível existência de observações outliers. Como consequência, a presença de outliers pode ocasionar a violação do pressuposto da homoscedasticidade em função da amplitude e ordem de grandeza dos valores das variáveis, o que exigirá a adoção de medidas adicionais visando sua correção.

Identifica-se, ainda, que algumas empresas não investiram "um único centavo" nas atividades de exploração e desenvolvimento da produção, enquanto que outras investiram "pesadamente" no de- 
senvolvimento da produção, chegando a mais de US\$ 24 bilhões num único período da amostra ou estão em plena campanha exploratória, com gastos superiores a US\$ 6 bilhões.

Tabela 3: Matriz de Correlação de Pearson - Valores Histórico

\begin{tabular}{|c|c|c|c|c|c|c|c|c|c|}
\hline & PREÇO & LPA & PLA & ATIVOE\&P & VLUCRO & CAPEX & GEXPLO & GDESEN & LUCROSEG \\
\hline PREÇO & 1 & & & & & & & & \\
\hline LPA & $0,721^{* * *}$ & 1 & & & & & & & \\
\hline PLA & $0,845^{\star * *}$ & $0,795^{\star * *}$ & 1 & & & & & & \\
\hline ATIVOE\&P & $0,438^{\star \star *}$ & $0,477^{\star \star *}$ & $0,490^{* * *}$ & 1 & & & & & \\
\hline VLUCRO & $0,296^{* \star *}$ & $0,444^{\star \star *}$ & $0,370^{* \star *}$ & $0,762^{* \star *}$ & 1 & & & & \\
\hline CAPEX & $0,385^{\star \star *}$ & $0,438^{\star \star *}$ & $0,442^{* * *}$ & $0,884^{* * *}$ & $0,707^{\star \star \star}$ & 1 & & & \\
\hline GEXPLO & $0,213^{\star * *}$ & $0,309^{* * *}$ & $0,312^{\star * *}$ & $0,752^{\star \star *}$ & $0,608^{\star \star *}$ & $0,765^{\star \star *}$ & 1 & & \\
\hline GDESEN & $0,348^{\star \star *}$ & $0,425^{\star \star \star}$ & $0,419^{* * *}$ & $0,860^{\star \star *}$ & $0,710^{\star \star *}$ & $0,866^{\star \star \star}$ & $0,803^{\star \star \star}$ & 1 & \\
\hline LUCROSEG & $0,373^{\star \star *}$ & $0,505^{\star \star *}$ & $0,398^{\star * *}$ & $0,875^{\star * *}$ & $0,752^{\star \star \star}$ & $0.819^{\star \star *}$ & $0,706^{\star * *}$ & $0,843^{\star * *}$ & 1 \\
\hline
\end{tabular}

Fonte: dados da pesquisa. Nota: PREÇO: preço das ações em t mais 3 meses, ajustado pelos dividendos e desdobramentos; LPA: lucro líquido por ação; PLA: patrimônio líquido por ação; ATIVOE\&P: total dos ativos do segmento de exploração e produção;VLUCRO:variação anual do lucro líquido; CAPEX:total dos gastos incorridos nos projetos de exploração e produção; GEXPLO: total dos gastos incorridos na fase de exploração do projeto; GDESEN: total dos gastos incorridos na fase de desenvolvimentodoprojeto;LUCROSEG;lucrolíquidodosegmentodeexploraçãoeprodução.Significância:***(1\%); ${ }^{* *}(5 \%) ;{ }^{*}(10 \%) . \mathrm{N}=559 \mathrm{observações.}$

Na Tabela 3 é possível identificar como as variáveis selecionadas para os testes da relevância das informações a valor histórico se relacionam entre si. Percebe-se que todas as variáveis explicativas apresentam correlação positiva com a variável dependente "preço", sendo que as variáveis "PLA"e "LPA" são as com maior relação: $72 \%$ e $85 \%$, respectivamente.

As demais variáveis não atingem mais do que $44 \%$ de correlação com a variável dependente, sendo a menor delas de $21 \%$ (GEXPLO), o que pode implicar em uma possível falta de significância estatística dessa variável, a ser constatada quando da obtenção dos resultados gerados pelos modelos econométricos selecionados.

A informação mais importante que se pode observar na matriz de correlação diz respeito à alta relação observada entre as algumas variáveis explicativas, que giram acima de 70\%. Tal situação pode ser explicada pelo fato de as variáveis "ATIVOE\&P"; "CAPEX"; "GEXPLO" e "GDESEN" serem da mesma natureza: a primeira corresponde à soma de vários "CAPEX" ao longo do tempo, que por sua vez representa a soma dos investimentos realizados na fase de exploração (GEXPLO) e de desenvolvimento da produção (GDESEN).

A principal consequência desse alto grau de correlação é a possível violação do pressuposto da multicolinearidade, o que implicou na realização do teste VIF (Variance Inflation Factor). O resultado do teste indica a não violação desse pressuposto, dado que o valor do teste VIF da maioria das variáveis ficou abaixo de 6,174. Apenas a variável ATIVOE\&P apresentou valor mais elevado, com teste VIF de 8,010 . $O$ atendimento desse pressuposto foi possível porque os dados foram transformados com o emprego do logaritmo natural.

A transformação da relação funcional das variáveis é um dos remédios apresentados por Corrar, Paulo e Dias Filho (2007) para correção da multicolinearidade, sem que, necessariamente, seja preciso a exclusão das variáveis problemáticas do modelo. 
A Tabela 4 contém as evidências dos testes realizados considerando o conjunto de informações baseados em valores históricos. Como pode ser observado, os parâmetros estimados pela regressão indicam um modelo com bom ajustamento, ou seja, de 79,37\% (R2 ajustado).

A regressão como um todo pode ser considerada válida dada à significância da estatística F. Os parâmetros foram estimados com a utilização da matriz de erros padrão robustos para correção da heterocedasticidade e da autocorrelação (HAC). Dado a quantidade de observações (559), recorreu-se ao teorema do limite central para relaxar o pressuposto da normalidade.

\begin{tabular}{|c|c|c|c|c|c|c|c|c|c|c|c|}
\hline \multirow{2}{*}{ Coef. } & \multirow{2}{*}{ Variáveis } & \multirow{2}{*}{$\begin{array}{c}\text { Sinal } \\
\text { Esperado }\end{array}$} & \multicolumn{3}{|c|}{ Efeitos Fixos } & \multicolumn{3}{|c|}{ Efeitos Fixos } & \multicolumn{3}{|c|}{ Efeitos Fixos } \\
\hline & & & Coef. & Erro Padrão & Sig. & Coef. & Erro Padrão & Sig. & Coef. & Erro Padrão & Sig. \\
\hline$\alpha$ & C & & 0,847 & 0,169 & 0,000 & 1,003 & 0,136 & 0,000 & 0,735 & 0,170 & 0,000 \\
\hline$\beta_{1}$ & LPA & + & 0,061 & 0,019 & 0,001 & 0,060 & 0,019 & 0,002 & 0,060 & 0,019 & 0,002 \\
\hline$\beta_{2}$ & PLA & + & 0,370 & 0,021 & 0,000 & 0,380 & 0,021 & 0,000 & 0,371 & 0,021 & 0,000 \\
\hline$\beta_{3}$ & ATIVOE\&P & + & 0,119 & 0,042 & 0,004 & - & - & - & 0,119 & 0,041 & 0,004 \\
\hline$\beta_{4}$ & VLUCROLIQ & + & $-0,029$ & 0,011 & 0,010 & $-0,024$ & 0,011 & 0,032 & $-0,028$ & 0,011 & 0,012 \\
\hline$\beta_{5}$ & CAPEX & + & 0,017 & 0,016 & 0,294 & 0,045 & 0,017 & 0,010 & 0,019 & 0,015 & 0,196 \\
\hline$\beta_{6}$ & GEXPLO & + & $-0,109$ & 0,024 & 0,000 & $-0,107$ & 0,023 & 0,000 & $-0,105$ & 0,024 & 0,000 \\
\hline$\beta_{7}$ & GDESEN & + & 0,015 & 0,032 & 0,623 & 0,013 & 0,033 & 0,698 & - & - & - \\
\hline$\beta_{8}$ & LUCROSEG & + & 0,003 & 0,017 & 0,883 & 0,023 & 0,016 & 0,152 & 0,005 & 0,017 & 0,772 \\
\hline & & & \multicolumn{2}{|c|}{$\mathrm{R}^{2}$ Ajustado } & $79,37 \%$ & \multicolumn{2}{|c|}{$\mathrm{R}^{2}$ Ajustado } & $78,90 \%$ & \multicolumn{2}{|c|}{$\mathrm{R}^{2}$ Ajustado } & $79,41 \%$ \\
\hline & & & \multicolumn{2}{|c|}{ Estatística F } & 15,8077 & \multicolumn{2}{|c|}{ Estatística F } & 15,6688 & \multicolumn{2}{|c|}{ Estatística F } & 15,9458 \\
\hline & & & \multicolumn{2}{|c|}{ Sig. Estatist. F } & 0,000 & \multicolumn{2}{|c|}{ Sig. Estatist. F } & 0,000 & \multicolumn{2}{|c|}{ Sig. Estatist. F } & 0,000 \\
\hline & & & \multicolumn{2}{|c|}{ Durbin-Watson } & 2,0768 & \multicolumn{2}{|c|}{ Durbin-Watson } & 2,1118 & \multicolumn{2}{|c|}{ Durbin-Watson } & 2,0738 \\
\hline & & & \multicolumn{2}{|c|}{ Observações } & 559 & \multicolumn{2}{|c|}{ Observações } & 566 & \multicolumn{2}{|c|}{ Observações } & 559 \\
\hline
\end{tabular}

Fonte: dados da pesquisa.

Nota: PREÇO: preço das ações em t mais 3 meses, ajustado pelos dividendos e desdobramentos; LPA: lucro líquido por ação; PLA: patrimônio líquido por ação; ATIVOE\&P: total dos ativos do segmento de exploração e produção; VLUCRO: variação anual do lucro líquido; CAPEX: total dos gastos incorridos nos projetos de exploração e produção; GEXPLO: total dos gastos incorridos na fase de exploração do projeto; GDESEN: total dos gastos incorridos na fase de desenvolvimento do projeto; LUCROSEG; lucro líquido do segmento de exploração e produção. Regressões estimadas com erros padrão robustos para heterocedasticidade e autocorreção (HAC).

Os resultados indicam que as variáveis "lucro por ação" e"patrimônio líquido por ação" são estatisticamente significantes, conforme previsto na teoria. Ou seja, tais informações são capazes de explicar o comportamento do valor de mercado da empresa (preço das ações), mostrando-se, portanto, relevantes. O sinal dos coeficientes também se mostrou de acordo com o esperado.

Quanto às informações a valores históricos, os resultados indicam relevância estatística das variáveis relacionadas aos "Ativos de E\&P", a "Variação do Lucro Líquido" e quanto ao montante dos "Gastos Exploratórios". Em relação à relevância da variável "ATIVOE\&P", os resultados confirmam as evidências apontadas por Harris e Ohlson (1987), Chung; Chicas e Pastena (1993), Boone e Raman (2007) e Asekomeh et al (2010), ou seja, de que a informação sobre os ativos identificados com o segmento de exploração e produção de óleo e gás é uma informação relevante para a avaliação dos preços das ações, mostrando, portanto, possuírem conteúdo informacional relevante. Confirma-se também o comportamento (sinal) do coeficiente estimado.

Os resultados quanto à relevância da variação absoluta do lucro líquido sobre o preço das ações confirmam os achados de Doran, Collins e Dhaliwal (1988), Quirin, Berry e O'Bryan (2000), Boone e Ra- 
man (2007) e Bryant (2003), exceto pelo sinal do coeficiente. Apenas em Duchac e Douthett (1997) que se encontra um resultado semelhante (variável estatisticamente relevante com coeficiente negativo).

Por fim, em relação aos gastos exploratórios, os resultados deste estudo quanto à relevância dessa variável sobre o preço das ações estão em linha com os achados de Boynton IV, Boone e Coe (1999) e Berry e Wright (2001), com a diferença do sinal negativo do coeficiente. Assim, os resultados indicam que uma alta na intensidade exploratória da empresa no período da pesquisa implicou uma precificação para baixo no preço das ações.

O pressuposto adotado seguiu o entendimento de que para as empresas manterem seu portfólio de ativos de óleo e gás, o que estaria relacionado com a expectativa de rentabilidade futura, é necessário investimento em exploração com vistas às descobertas de novas reservas de óleo e gás.

No entanto, os resultados obtidos permitem outra interpretação partindo dos argumentos de que uma das características do setor petrolífero é a de que não existe uma correlação clara entre a magnitude dos gastos incorridos e qualquer valor resultante em reservas (Writh \& Gallun, 2008; Santos, Santos \& Silva, 2011).

Outra consideração que pode ser feita diz respeito ao fato de que a atividade petrolífera é de alto risco, de forma que um aumento considerado nos investimentos em exploração implica também considerar que partes desses investimentos não resultarão em descobertas viáveis economicamente, sendo uma realidade mais severa em períodos de baixa no preço do barril de petróleo.

No período da pesquisa observaram-se variações relevantes no preço do barril de petróleo, que em 2008 saiu de uma cotação de US\$ 132,72 para US\$ 39,95 o barril em função da crise financeira, tendo como consequência reconhecimento de perdas por impairment significativas (Santos, Santos \& Silva, 2011) e que podem ter afugentado os investidores com reflexos negativos no preço das ações das empresas, dado que o risco das empresas que investiram pesado em exploração no período aumentou frente à queda no preço do barril.

Estimaram-se ainda dois modelos adicionais, um excluindo a variável "ATIVOE\&P" e outro sem a variável "GDESEN", dado o teste VIF, que apesar de se encontrar numa faixa de aceitabilidade, apresenta-se como multicolinearidade moderada. Não se observaram alterações qualitativas significativas. As variáveis "VLUCROLIQ"e "GEXPLO" mantiveram-se significativas e com sinal negativo. A única informação relevante é a de que, quando se exclui a variável relacionada a "Ativos de E\&P", o "CAPEX" passa a apresentar significância estatística, indicando que, de fato, tais variáveis estão correlacionadas fortemente, como já observado anteriormente.

Apresentados os resultados, é possível inferir que, de certa forma, além do lucro líquido e do patrimônio líquido, algumas informações específicas do setor petrolífero mensuradas a valores históricos são úteis aos usuários da informação em suas decisões econômicas, ou seja, que o mercado de capitais (investidores) leva em conta tais informações mensuradas a valores históricos em suas decisões econômicas, as quais estão refletidas nos preços das ações das empresas da amostra (valor de mercado). Em outros termos, que essas variáveis possuem conteúdo informacional relevante.

Os resultados também reforçam os pressupostos de Ohlson (1995) de que o valor de mercado da empresa é função das variáveis contábeis (lucro líquido e patrimônio líquido), sendo que as demais variáveis contábeis relevantes "ativos de exploração e produção"; "variação do lucro líquido" e "gastos exploratórios" contribuem incrementando a relevância dessas variáveis contábeis mensuradas a valores históricos.

Assim, reportando-se à hipótese $\mathrm{H} 1$, tem-se a seguinte conclusão: 
Informações contábeis reportadas nas demonstrações financeiras e em notas complementares exigidas de empresas petroliferas e mensuradas a valores históricos são relevantes para a avaliação dos preços das ações.

Na segunda parte do estudo, foca-se na investigação da relevância de algumas informações não contábeis que são atualmente publicadas pelas empresas petrolíferas. A Tabela 5 evidencia a correlação entre as variáveis selecionadas. Quanto ao relacionamento com a variável dependente "PREÇO", observa-se que apenas o lucro líquido por ação e o patrimônio líquido por ação mantêm forte relação positiva, como desejado.

As variáveis não contábeis não chegam a atingir 17\% de correlação, inclusive a variável FCDP mostra-se não correlacionada estatisticamente com a variável dependente. Além disso, a correlação da variável "custo da descoberta" (FINDCOST) atende a expectativa inicial, mostrando um relacionamento negativo, ou seja, quanto menor o custo da descoberta, maior a expectativa futura de bons resultados, direcionado o preço das ações para cima.

Tabela 5: Matriz de Correlação de Pearson - Itens de Divulgação

\begin{tabular}{c|c|c|c|c|c|c|c|c}
\hline & PREÇ0 & LPA & PLA & QTRESPROV & VQTRESPROV & FCDP & TAXASUC & FINDCOST \\
\hline PREÇO & 1 & & & & & & & \\
\hline LPA & $0,736^{* * *}$ & 1 & & & & & & \\
\hline PLA & $0,828^{* * *}$ & $0,787^{* * *}$ & 1 & & & & & \\
\hline QTRESPROV & $0,129^{* * *}$ & $0,230^{* * *}$ & $0,164^{* * *}$ & 1 & & & & \\
\hline VQTRESPROV & $0,165^{* * *}$ & $0,187^{* * *}$ & $0,156^{* * *}$ & $0,714^{* * *}$ & 1 & & & \\
\hline FCDP & 0,088 & $0,195^{* * *}$ & $0,149^{* * *}$ & $0,929^{* * *}$ & $0,639^{* * *}$ & 1 & & \\
\hline TAXASUC & $0,118^{* *}$ & 0,033 & 0,069 & $-0,039$ & 0,081 & $-0,075$ & 1 & \\
\hline FINDCOST & $-0,153^{* * *}$ & $-0,034$ & $-0,054$ & $-0,139^{* * *}$ & $-0,248^{* * *}$ & $-0,064$ & $-0,213^{* * *}$ & \\
\hline
\end{tabular}

Fonte: dados da pesquisa

Nota: PREÇO: preço das ações em $t$ mais 3 meses, ajustado pelos dividendos e desdobramentos; LPA: lucro líquido po ação: PLA: patrimônio líquido por ação: OTRESPROV: volume de reservas provadas; VQRESPROV: variação anual no volume de reservas provadas; FCDP: fluxo de caixa descontado padronizado decorrente das reservas; TAXASUC: taxa de sucesso exploratório; FINDCOST: custo da descoberta por barril. Significância: *** (1\%); ** (5\%); * (10\%). N= 369 observações.

A análise da correlação entre as variáveis explicativas não indica, a priori, a presença da multicolinearidade grave. A exceção fica por conta da relação entre"FCDP"e "QTRESPROV" que apresenta índice de 93\%. Dado que a valor do fluxo de caixa descontado padronizado depende grandemente da quantidade de óleo e gás existente no reservatório, esse relacionamento chega a fazer sentido.

Para dirimir possíveis dúvidas que pudessem existir quanto ao problema da multicolinearidade, fez-

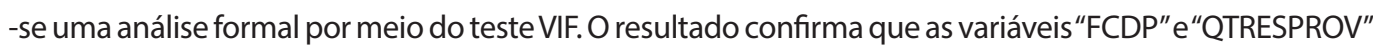
são as que apresentam maior valor: 7,595 e 9,123, respectivamente, mas dentro da aceitabilidade de multicolinearidade moderada. O valor VIF das demais variáveis repousou no intervalo entre 1,076 a 2,708.

Da mesma forma, como na primeira parte do estudo, também se realizou regressões adicionais. Primeiramente se excluiu a variável "QTRESPROV" e, posteriormente, a variável "FCDP". Optou-se por essa estratégia metodológica, tendo em vista que essas duas variáveis apresentam praticamente a mesma correlação com a variável "PREÇO" e foram as que apresentaram maior valor VIF. Os resultados das regressões podem ser observados na Tabela 6. 
Tabela 5: Matriz de Correlação de Pearson - Itens de Divulgação

\begin{tabular}{|c|c|c|c|c|c|c|c|c|c|c|c|}
\hline \multirow{2}{*}{ Coef. } & \multirow{2}{*}{ Variáveis } & \multirow{2}{*}{$\begin{array}{c}\text { Sinal } \\
\text { Esperado }\end{array}$} & \multicolumn{3}{|c|}{ Efeitos Fixos } & \multicolumn{3}{|c|}{ Efeitos Fixos } & \multicolumn{3}{|c|}{ Efeitos Fixos } \\
\hline & & & Coef. & Erro Padrão & Sig. & Coef. & Erro Padrão & Sig. & Coef. & Erro Padrão & Sig. \\
\hline$\alpha$ & c & & 2,461 & 0,263 & 0,000 & 2,229 & 0,250 & 0,000 & 1,765 & 0,213 & 0,000 \\
\hline$\omega_{1}$ & LPA & + & 0,097 & 0,032 & 0,003 & 0,103 & 0,033 & 0,002 & 0,078 & 0,031 & 0,012 \\
\hline$\omega_{2}$ & PLA & + & 0,312 & 0,031 & 0,000 & 0,309 & 0,032 & 0,000 & 0,329 & 0,032 & 0,000 \\
\hline$w_{3}$ & FINDCOST & $(-)$ & $-0,023$ & 0,010 & 0,027 & $-0,027$ & 0,011 & 0,012 & $-0,030$ & 0,012 & 0,011 \\
\hline$\omega_{4}$ & TAXASUC & + & 0,059 & 0,069 & 0,396 & 0,054 & 0,068 & 0,426 & 0,092 & 0,073 & 0,205 \\
\hline$\omega_{5}$ & QTDRESPROV & + & 0,060 & 0,026 & 0,022 & - & - & - & $-0,027$ & 0,013 & 0,031 \\
\hline$\omega_{6}$ & VQTDRESPROV & + & 0,025 & 0,012 & 0,042 & 0,036 & 0,011 & 0,002 & 0,028 & 0,013 & 0,023 \\
\hline$\omega_{7}$ & FCDP & + & $-0,206$ & 0,052 & 0,000 & $-0,096$ & 0,024 & 0,000 & - & - & - \\
\hline & & & & ustado & $80,69 \%$ & & ustado & $80,29 \%$ & & ustado & $79,35 \%$ \\
\hline & & & & stica F & 12,223 & & ística F & 12,020 & & stica F & 11,4842 \\
\hline & & & Sig. & tatist. F & 0,000 & & tatist. F & 0,000 & Sig. & tatist. F & 0,000 \\
\hline & & & Durb & Watson & 2,3640 & Durb & -Watson & 2,3462 & Durb & Watson & 2,3108 \\
\hline & & & Obs & vações & 369 & & vações & 369 & & vações & 372 \\
\hline
\end{tabular}

Fonte: dados da pesquisa.

Nota: PRECO: preço das ações em t mais 3 meses, ajustado pelos dividendos e desdobramentos; LPA: lucro líquido por ação; PLA: patrimônio líquido por ação; FINDCOST: custo da descoberta por barril; TAXASUC: taxa de sucesso exploratório; QTRESPROV: volume de reservas provadas; VQRESPROV: variação anual no volume de reservas provadas; FCDP: fluxo de caixa descontado padronizado decorrente das reservas.

O modelo contou com 369 observações e apresentou grau de ajustamento de 80,69\%, podendo, ainda, ser considerada válida como um todo dada à significância da estatística F. Os parâmetros também foram estimados com a utilização da matriz de erros padrão robustos para correção da heterocedasticidade e da autocorrelação (HAC) e o pressuposto da normalidade foi relaxado, tendo por base o teorema do limite central.

As variáveis "LPA" e "PLA" mais uma vez se mostraram significativas a 1\%, sendo $\omega 1>\omega 2$ como predito pela teoria (Lopes, 2001). Quanto às variáveis de interesse do estudo, apenas a variável "taxa de sucesso exploratório" não mostrou significância estatística, sendo as demais significantes ao nível de $5 \%$. Esse resultado indica que tais informações normalmente divulgadas por empresas petrolíferas, sejam de forma obrigatória ou voluntária, são úteis para influenciar, de forma incremental, o preço das ações da empresa.

Detalhando os achados, a variável "custo da descoberta" (FINDCOST) apresenta-se como estatisticamente relevante e seguiu o sinal esperado. O resultado indica que a medida "FINDCOST", popularmente utilizada, possui relevância na avaliação da performance da empresa e, consequentemente, na sua precificação. Ou seja, quanto menor for o custo de se descobrir um barril de petróleo, mais eficiente a empresa está sendo e, dessa forma, a probabilidade de se criar valor para o acionista aumentaria mais rapidamente, conforme analisam Quirin, Berry e O'Bryan (2000) e expresso no DPEA (IASB, 2010a). 
Apesar de ser uma informação baseada no custo histórico (parte do montante dos gastos exploratórios incorridos no período) e da controvérsia quanto a sua utilidade (dado às diversas formas de cálculo), têm-se mostrado a relevância dessa informação, o que é confirmado neste estudo e reforça os achados obtidos por Boynton IV, Boone e Coe (1999); Quirin, Berry e O'Bryan (2000) e Misund, Asche e Osmundsen (2008), os quais indicam que o custo da descoberta é um indicador utilizado pelos participantes do mercado de capitais no processo de avaliação de empresas do setor petrolífero e que tem influência sobre o preço das ações.

A informação quanto às estimativas do volume total das reservas provadas (QTDRESPROV) são úteis para o mercado de capitais e são capazes de influenciar o preço das ações. Essas evidências corroboram os achados de Berry, Hasan e O'Bryan (1998); Berry e Wrigth (2001); Misund, Osmundsen e Asche (2005) e, em parte, os resultados de Clinch e Magliolo (1992), além de confirmarem a percepção expressa no DPEA de que, de fato, os analistas utilizam essa informação como input em seus modelos de avaliação e precificação.

As mudanças nas estimativas, sumarizadas na variável variação no volume de reservas provadas (VQTDRESPROV), também se mostraram relevantes para valoração da empresa. Esse resultado confirma a suposição do grupo de trabalho contida no DPEA de que a divulgação das explicações nas mudanças no volume de reservas da empresa de um ano para outro deve ajudar os usuários a obterem um meIhor entendimento da natureza e extensão das incertezas associadas com as estimativas das reservas (IASB, 2010a).

Essas duas primeiras evidências reforçam a concepção de que os dados sobre as reservas das empresas petrolíferas devem fazer parte do rol de informações a serem exigidas em uma futura norma internacional, independentemente se os ativos serão mensurados a valores históricos ou a valores justos. Mais particularmente, essas evidências confirmam a pesquisa realizada pelo grupo de trabalho de que as demonstrações financeiras forneceriam informações úteis sobre os ativos de óleo e gás se uma quantidade substantiva de informações sobre as reservas fosse exigida (IASB, 2010a).

As evidências sugerem ainda que o valor das reservas mensuradas utilizando premissas padronizadas mostra-se útil aos usuários em suas decisões econômicas. Trata-se de uma medida grandemente criticada (Wright \& Brock, 1999; Wright \& Gallun, 2008) em função de apresentar um número que não representa o valor justo dos ativos de óleo e gás, dado que as premissas utilizadas não refletem a realidade econômica e operacional futura da empresa.

O grupo de trabalho do IASB também apresenta severas críticas à mensuração padronizada, mas não avança no sentido de se propor um modelo que suporte a estimativa do valor justo das reservas de óleo e gás. Com isso, se rende à mensuração padronizada, empregando-o na proposta apresentada no DPEA, pequenas alterações naquilo que já é exigido pelo FASB e que acaba sendo seguido pelas empresas do setor como melhor prática de divulgação.

Apesar das críticas, diversas pesquisas têm mostrado a relevância da mensuração padronizada das reservas, suportando os resultados desse estudo: Doran, Collins e Dhaliwal (1988); Chung, Ghicas e Pastena (1993); Raman e Tripathy (1993); Alciatore (1993); Spear (1996); Berry, Hasan e O'Bryan (1998); Bryant (2003); e Santos e Silva (2014). A única ressalva que se faz diz respeito ao sinal do coeficiente, que se mostrou diferente do esperado.

Em função dos baixíssimos valores dos coeficientes e alta concentração no intercepto (a), pode-se levantar a suposição de que a multicolinearidade moderada observada nas variáveis "QTRESPROV" $\mathrm{e}$ "FCDP" possa ter influenciado o resultado da regressão. Nesse contexto, duas novas regressões foram realizadas, levando-se em conta a exclusão dessas variáveis. 
Analisando os resultados, tal suposição não se confirmou, dado que, excluída uma das duas variáveis do modelo, as alterações em relação aos coeficientes estimados e aos demais parâmetros do modelo ( $R^{2}$ ajustado, por exemplo) foram mínimas.

Esperava-se coeficiente positivo para a variável "FCDP", mas o resultado obtido não atendeu as expectativas iniciais. A inferência que pode ser realizada diz respeito ao fato que as premissas para valoração dos fluxos de caixa são predefinidas, o que acaba não mantendo relação com a realidade, conforme críticas de Wright e Brock (1999) e Wright e Gallun (2008). Isso se torna relevante em um cenário de grande volatilidade no preço do barril, com tendência de queda, implicando no aumento do risco das empresas petrolíferas.

Com premissas padronizadas esse aumento do risco, por exemplo, não impactou a taxa de desconto dos fluxos de caixa, uma vez que a mesma é padronizada em 10\% ao ano.

Mas mais relevante pode-se apontar o preço do barril utilizado na estimativa do "FCDP". Pelas práticas vigentes até 2011, o preço de referência era o valor do barril negociado no último dia do ano. Como já explicitado, em 2008 o preço fechou a US\$39,95 por barril, o menor patamar durante o período deste estudo. Tal situação implicou em queda drástica nos valores dos "FCDP" de 2008, seguido a variação negativa no preço do barril em relação a 2009 de menos 56,1\%.

Acredita-se que esse fator tenha contribuído para inverter o sinal do coeficiente apresentado. Contribui para esse entendimento os achados de Santos e Silva (2014), que em um estudo sobre relevância da informação, trabalhando amostras de empresas que seguem os métodos dos esforços bem sucedidos e da capitalização total para o período de 2005 a 2013.

A contribuição reside no fato de os resultados apontarem coeficientes significativos e positivos para o fluxo de caixa descontado padronizado das reservas e, principalmente, pelo estudo abranger os períodos de 2012 e 2013, períodos esses sob as novas regras da SEC motivada pelos episódios 2008 que estabelecem que o preço a ser considerado nas estimativas deve corresponder ao preço médio dos últimos 12 meses, no lugar do preço de uma única data.

Assim, apesar de ser uma informação relevante, a distorção em premissas fundamentais para a estimativa do fluxo de caixa descontado das reservas petrolíferas pode ter comprometido a relação da informação (FCDP) com o preço das ações neste estudo.

Conjugando os resultados encontrados para "QTRESPROV" $\mathrm{e}$ "FCDP", entretanto, estão em linha com os achados de Berry, Hasan e O'Bryan (1998), que também não conseguiram distinguir categoricamente qual das duas informações seria mais relevantes: a quantidade ou o valor padronizado das reservas. $\mathrm{Na}$ pesquisa realizada pelos autores, quando analisadas isoladamente, as duas variáveis foram consideradas estatisticamente relevantes (Berry, Hasan \& O'Bryan, 1998).

Mesmo considerando que as estimativas sobre a quantidade de reservas não são confiáveis e que o modelo de valoração dessas quantidades é falho, como revelam Clinch e Magliolo (1992) para justificar os seus achados, as evidências indicam que as informações sobre reservas, seja sua quantidade (e variação), seja em valores padronizados, representam informações úteis para o mercado de capitais e são capazes de influenciar o preço das ações das empresas.

Dessa forma, reportando-se à hipótese $\mathrm{H}_{2^{\prime}}$ tem-se a seguinte conclusão:

Informações complementares reportadas por empresas petroliferas relacionadas às reservas de óleo e gás (volume, valor padronizado e custo para encontrá-las) são relevantes para a avaliação dos preços das ações. 
Considerando os dois grandes focos de discussão tratados neste estudo: (1) mensuração a valor histórico versus mensuração a valor justo e (2) divulgação obrigatória de informações contábeis e não contábeis; os resultados obtidos implicam na constatação de que o mercado, usuário primário das informações contábeis, atribui relevância para o modelo contábil em vigor aplicado às empresas petrolíferas, ou seja, o atual conjunto de informações disponibilizado ao mercado possui conteúdo informacional relevante.

\section{CONSIDERAÇÕES FINAIS}

As evidências empíricas trazidas pelo estudo permitem subsidiar, primeiramente, a refutação do argumento contido no DPEA de que as informações a custo histórico dos ativos de óleo e gás (gastos incorridos para encontrar/desenvolver um depósito petrolífero) contidos nas demonstrações contábeis não geram informação útil aos usuários das informações contábeis, ou seja, que não são capazes de contribuir para predizer fluxos de caixa futuros e, consequentemente, valorar a empresa.

Esse argumento da baixa relevância do custo histórico é prevalecente no DPEA em função da quase inexistência de correlação entre os gastos incorridos para explorar e desenvolver as reservas (valor que configura no ativo) e o valor econômico das mesmas (valor justo). Contudo, as evidências trazidas nesse estudo mostram o contrário.

Primeiramente, as informações relacionadas ao lucro líquido e ao patrimônio líquido, em todas as situações, mostraram-se relevantes, ou seja, as informações contábeis de empresas petrolíferas são capazes de influenciar as decisões econômicas dos usuários.

Para consolidar a importância das informações baseadas em números contábeis divulgados de acordo com o custo histórico, as evidências mostraram também que a variável "gastos exploratórios", por exemplo, foi estatisticamente relevante, permitindo se inferir que tais informações representativas dos investimentos realizados em projetos exploratórios são utilizadas pelos participantes do mercado de capitais em suas decisões econômicas. Esse resultado advoga em favor do custo histórico, contrariando diversas críticas quanto ao modelo contábil aplicável às empresas petrolíferas.

Na segunda dimensão deste estudo, buscou-se evidenciar que o atual conjunto de informações divulgadas obrigatoriamente pelas empresas petrolíferas eram relevantes e usadas pelos usuários da informação. Os resultados dão conta de que a hipótese formulada $(\mathrm{H} 2)$ não pode ser rejeitada, uma vez que as variáveis selecionadas foram consideradas estatisticamente relevantes. Apenas a variável "taxa de sucesso exploratório" pode ser descartada.

A não rejeição dessa hipótese, como sugerem as evidências, advoga contra a proposta do IASB contida no DPEA em aumentar o nível de divulgação obrigatória por parte das empresas e pode alimentar os argumentos dos grupos de interesses envolvidos, gerando resistências para que o IASB coloque em prática sua proposta. O resultado da consulta pública realizada corroboram esse entendimento, no qual fica patente a ampla rejeição da proposta pelos participantes da consulta (Santos \& Santos, 2014).

Pode-se inferir, dessa forma, que o atual modelo de reconhecimento das transações econômicas das empresas petrolíferas, bem como o atual conjunto de informações divulgadas, parece satisfazer as necessidades informacionais dos participantes do mercado de capitais e implicam em considerar que qualquer evolução no status quo vigente terá que ser bem "costurado" pelo IASB, pois os preparadores teriam argumentos empíricos para considerar, por exemplo, que o custo de preparação das informações considerando um novo modelo dificilmente justificaria os possíveis benefícios de tais informações. 
Motivado pela tentativa do IASB em deliberar definitivamente sobre o tema, uma vez que já vem tentando desde 1998, a revisão do IFRS 6 constou na agenda de trabalho do normatizador internacional, mas encontra-se paralisado no IASB tendo em vista os projetos relacionados as normas sobre reconhecimento de receitas, arrendamento mercantil e estrutura conceitual vem tomando grandemente o tempo do board e não existe perspectiva a curto e médio prazos de continuidade do projeto com a emissão de um Exposure Draft (minuta de norma).

Nesse contexto as considerações de Cortese e Irvine (2010) de que o IASB foi capturado pelas empresas petrolíferas com vistas à manutenção de seus interesses ainda parece consistente e ganha complexidade, dado que a liberdade para a definição da política contábil permitida pelo IFRS 6 levou ao surgimento de diversos modelos de reconhecimento, conforme aponta Sturdy e Cronjé (2014). Os autores identificaram, além dos métodos dos esforços bem sucedidos, capitalização total e área de interesse, mais três derivações: full-expense method; expense-and-reinstate method e area-of-interest-with-provision method.

Não se pode deixar de se considerar que a proposta apresentada pelo IASB é inovadora e colocam em cheque os modelos atuais de reconhecimento, mensuração e divulgação utilizados e, ainda, propõe um modelo contábil que impactaria todas as empresas do setor, sejam elas seguidoras do método dos esforços bem sucedidos, da capitalização total ou de qualquer outro. Em função disso, presume-se que o IASB terá que fazer um esforço muito maior para colocar em prática sua proposta, reforçando a tese de manutenção do status quo vigente.

Os resultados e conclusões derivadas possuem o viés do modelo econométrico utilizado. Assim, outros estudos são possíveis a partir de novas modelagens que visem aferir a relevância e qualidade das informações contábeis, considerando às atualmente disponibilizadas pelas empresas frente à proposta do IASB.

Nesse particular, estudos relacionados a conservadorismo, gerenciamento de resultados, persistência dos lucros, estudos de eventos, são pertinentes e possíveis de serem realizados. Também existe margem para estudos teóricos que venham a confrontar ou defender conceitualmente a proposta do IASB, que tem como pano de fundo o conceito de ativo como ponto fundamental. Da mesma forma, estudos teóricos com vistas à definição de modelos para a determinação do valor justo das reservas petroliferas e minerais podem ser realizados. 
Aboody, David. \& Lev, Baruch. (1998). The value relevance of intangibles: the case of software capitalization. Journal of Accounting Research. 36 (supplement), pp. 161-191.

Adkerson, Richard C. (1979). Can reserve recognition accounting work? Journal of Accountancy. 148(3), pp. 72-81.

Alciatore, Mimi L. New evidence on SFAS n 69 and the components of the change in reserve value. The Accounting Review. v. 68, n. 3, p. 639-658. 1993.

Amir, Eli. \& Lev, Baruch. (1996). Value-relevance of nonfinancial information: the wireless communications industry. Journal of Accounting and Economics. 22, pp. 3-30.

Asekomeh, Ayodele O. et al. (2010). Decision-usefulness of oil and gas historical cost and supplementary present value disclosures - a revisit of the misspecification hypothesis. Petroleum Accounting and Finance Management Journal. 29(1), pp. 19-70.

Barth, Mary E. (2006). Including estimates of the future in today's financial statements. Accounting Horizons. 20 (3), pp. 271-285.

Barth, Mary E., Landsman, Wayne R. \& Lang, Mark H. (2008). International Accounting Standards and Accounting Quality. Journal of Accounting Research. 46(3).

Beaver, William H. (1998). Financial reporting: an accounting revolution. New Jersey: Printice-Hall.

Berry, Kevin T., Hasan, Tanweer. \& O'Bryan, David. (1998). Relative information content of proved reserves: the BOEs-revenue versus BOEs-energy. Journal of Energy Finance \& Development. 3(1), pp. 1-11.

Berry, Kevin T. \& Wright, Charlotte J. (2001). The value relevance of oil and gas disclosures: an assessment of the market's perception of firms' effort and ability to discover reserves. Journal of Business Finance \& Accounting. 28(5), pp. 741-769.

Boone, Jeffery P. (1998). Oil and gas reserve value disclosures and bid-ask spreads. Journal of Accounting and Public Policy. 17, pp. 55-84.

Boone, Jeffery P. (2002). Revisiting the reportedly weak value relevance of oil and gas asset present value: the roles of measurement error; model misspecification, and time-period idiosyncrasy. The Accounting Review. 77(1), pp. 73-106.

Boone, Jeffery P., Luther, Robert G. \& Raman, K. K. (1998). Market microstructure effects of U.S.-Canada differences relating to reserve-based accounting disclosures. Journal of International Accounting, Auditing \& Taxation. 7(2), pp. 195-214. 
Boone, Jeffery P. \& Raman, K.K. (2007). Does implementation guidance affect opportunistic reporting and value relevance of earnings? Journal of Accounting and Public Policy. 26, pp. 160-192.

Boynton Iv, Charles E., Boone, Jeffery P. \& Coe, Teddy L. (1999). Evaluating the exploration efficiency of oil and gas firms using SFAS 69 supplemental disclosures. Journal of Energy Finance and Development. 4, pp. 1-27.

Brock, Horace R., Carnes, Martha Z. \& Justice, Randol. (2007). Petroleum accounting: principles, procedures \& issues. 6. ed. Denton, Texas: PricewaterhouseCoopers/Professional Development Institute.

Brown, Stephen., Lo, Kin. \& Lys, Thomas. (1999). Use of R2 in accounting research: measuring changes in value relevance over the last four decades. Journal of Accounting and Economics. 28, pp. 83-115.

Bryant, Lisa. (2003). Relative value relevance of the successful efforts and full cost accounting method in the oil and gas industry. Review of Accounting Studies. 8, pp. 5-28.

Cardoso, Ricardo L., Saravia, Enrique., Tenório, Fernando G. \& Silva, Marcelo A. (2009). Regulação da contabilidade: teorias e análise da convergência dos padrões contábeis brasileiros aos IFRS. Revista de Administração Pública. 43(4), pp. 773-799.

Chung, Dennis Y. (1999). The informational effect of corporate lobbying against proposed accounting standards. Review of Quantitative Finance and Accounting. 12(3), pp. 243-269.

Chung, Kwang-Hyun., Ghicas, Dimitrios. \& Pastena, Victor. (1993). Lenders' use of accounting information in the oil and gas industry. The Accounting Review. 68(4), pp. 885-895.

Clinch, Greg. \& Magliolo, Joseph. (1992). Market perceptions of reserve disclosures under SFAS n 69 . The Accounting Review. 67(4), pp. 843-860.

Collins, Daniel W., Maydew, Edward L. \& Weiss, Ira S. (1997). Changes in the value-relevance of earning and book values over the past forty years. Journal of Accounting and Economics. 24, pp. 39-67.

Connor, Joseph E. (1979). Reserve recognition accounting: fact or fiction? Journal of Accountancy. 148(3), pp. 92-99.

Cooper, Kerry et al. (1979). Reserve recognition accounting: a proposed disclosure framework. Journal of Accountancy. 148(3), pp. 82-91.

Corrar, Luiz J., Paulo, Edilson. \& Dias Filho, José M. (Coords.) (2007). Análise multivariada. São Paulo: Atlas.

Cortese, Corinne L. \& Irvine, Helen. (2010). Investigating international accounting standard setting: the black box of IFRS 6. Research in Accounting Regulation. 22, pp. 87-95.

Doran, B. Michael., Collins, Daniel W. \& Dhaliwal, Dan S. (1988). The information of historical cost earnings relative to supplemental reserve-based accounting data in the extractive petroleum industry. The Accounting Review. 63(3), pp. 389-413. 
Duchac, Jonathan E., Douthett Jr. \& Edward B. (1997). The effect of accounting for oil and gas reserves on the relation between returns and earnings. Journal of Accounting and Finance Research. 4(2), pp. 20-32.

Gujarati, Damodar N. \& Porter, Dawn C. (2011). Econometria básica. 5. ed. Porto Alegre: AMGH.

Harris, Trevor S. \& Ohlson, James A. (1987). Accounting disclosures and the market's valuation of oil and gas properties. The Accounting Review. 57(4), pp. 651-670.

Holthausen, Robert W. \& Watts, Ross L. (2001). The relevance of value relevance literature for financial accounting standard setting. Journal of Accounting and Economics. 31, pp. 3-75.

IASB. International Accounting Standards Board (2010a). Discussion Paper Extractive Activities. Abril.

IASB. International Accounting Standards Board. (2010b). Extractive Activities - Comment Letter Summary. Staff Paper. October.

lyengar, Raghavan J. (1999). Simultaneity of accounting choice and exploration expenditures in the oil and gas industry. Petroleum Accounting and Financial Management Journal. 18(1), pp. 32-48.

Kennedy, Dennis T. \& Hyon, Yong-Ha. (1992). Do RRA earnings improve the usefulness of reported earnings in reflecting the performance of oil and gas producing firms? Journal of Accounting, Auditing \& Finance. 7(3), pp. 335-356.

Lev, Baruch. (1988). Toward a theory of equitable and efficient accounting policy. The Accounting Review. 63(1), pp. 1-22.

Lilien, Steven. \& Pastena, Victor. (1982). Determinants of intramethod choice in the oil and gas industry. Journal of Accounting and Economics. 4, pp. 145-170.

Lopes, Alexsandro B. (2001). A relevância da informação contábil para o mercado de capitais: o modelo de Ohlson aplicado à Bovespa. 2001. Tese (Doutorado em Controladoria e Contabilidade) - Programa de Pós-Graduação em Ciências Contábeis, Faculdade de Economia, Administração e Contabilidade da Universidade de São Paulo. São Paulo.

Martins, Eliseu. (2014). Inversão de papéis. Revista Contabilidade \& Finanças. 25(65), pp. 124-144.

Misund, Bard., Asche, Frank. \& Osmundsen, Petter. (2008). Industry upheaval and valuation: empirical evidence from the international oil and gas industry. The International Journal of Accounting. 43, pp. 398-424.

Misund, Bard., Osmundsen, Petter. \& Asche, Frank. (2005). The value-relevance of accounting figures in the international oil and gas industry - cash flows or accruals? In: Annual North American Conference of the USAEE/IAEE, 25, Anais ... Denver: IAEE. 
Murcia, Fernando Dal-Ri. \& Santos, Ariovaldo dos. (2009). Fatores determinantes do nível de disclosure voluntário de companhias abertas no Brasil. Revista de Educação e Pesquisa em Contabilidade (Repec). 3(2), pp. 72-95.

Nichols, Linda M. (2009). Moving the upstream industry to IFRS. Petroleum Accounting and Finance Management Journal. 28(3), pp. 1-21.

Ohlson, James A. (1995). Earnings, book values, and dividends in equity valuation. Contemporary Accounting Research. 11, pp. 661-687.

Raman, K. K \& Tripathy, Niranjan. (1993). The effect of supplemental reserve-based accounting data on the market microstructure. Journal of Accounting and Public Policy.12, pp. 113-133.

Russell, Alex. \& Jenkins, Linda. (2010). Reflections on the attempt to set a comprehensive international accounting standard for the oil and gas industry. Petroleum Accounting and Financial Management Journal. 29(29), pp. 16-29.

Santos, Odilanei M. \& Silva, Paula D. A. (2014). Os métodos contábeis dos esforços bem sucedidos e capitalização total: um estudo sob a perspectiva do value relevance. Enfoque: Reflexão Contábil. 33(2), pp. 121-138.

Santos, Odilanei M. \& Santos, Ariovaldo dos. (2014). Lobbying na regulação contábil: evidências do setor petrolífero. Revista Contabilidade \& Finanças. 25(65). pp. 124-144.

Santos, Odilanei M., Santos, Ariovaldo dos. \& Silva, Paula D. A. (2011). Reconhecimento de perdas para redução ao valor recuperável de ativos: impairment em ativos de exploração e produção de petróleo. Brazilian Business Review - BBR. 8(2), pp. 68-95.

Spear, Nasser A. (1996). The market reaction to the reserve-based value replacement measures of oil and gas producers. Journal of Business Finance \& Accounting. 23(7), pp. 953-974.

Sturdy, J. \& Cronjé, C. (2014). An analysis of the accounting practices of junior exploration companies in South Africa. Journal of Economic and Financial Sciences. 7(3), pp. 681-696.

Wright, Charlotte J. \& Brock, Horace R. (1999). Relevance versus reliability of oil and gas reserve quantity and value disclosures: the results of two decades of research. Petroleum Accounting and Finance Management Journal. 18(3), pp. 86-110.

Wright, Charlotte J. \& Gallun, Rebecca A. (2008). Fundamentals of oil \& gas accounting. 5. ed., Tulsa, Oklahoma: PennWell.

i Atualmente o SFAS 69, assim como o SFAS 19, foi reclassificado para a nova padronização do FASB, ASC 932 - Accounting Standard Codification 932 - Extractive 